\title{
COMO OS ALUNOS DE ENGENHARIA ELÉTRICA PODEM SE INTERESSAR POR MECÂNICA DAS ESTRUTURAS?
}

DOI: 10.37702/2175-957X.COBENGE.2021.3636

Bruna Wendhausem Enne - brunawe@usp.br

Universidade de São Paulo

Rua Nossa Senhora de Lourdes 150

24360-420 - Niterói - RJ

Osvaldo Shigueru Nakao - nakao@usp.br

USP

Alameda Jauaperi 1096

04523-014 - São Paulo - SP

Jose Aquiles Baesso Grimoni - jose.grimoni@usp.br

Universidade de Sao Paulo

Rua Pereira do Lago - 360158

05590-000 - Sao Paulo - SP

Resumo: A estratégia de Aprendizagem Baseada em Projetos (ABP), destaca-se no que se refere à capacidade de engajar os alunos ativamente em seu aprendizado e vem sendo altamente recomendada como uma das melhores práticas educacionais do século XXI. O presente artigo tem como objetivo descrever os resultados obtidos por essa estratégia na disciplina "Fundamentos de Mecânica das Estruturas (PEF 3208)", ministrada para alunos em Engenharia Elétrica na Escola Politécnica da Universidade de São Paulo (Poli USP). Avaliaram-se os resultados da pesquisa sobre a percepção dos alunos quanto à contribuição do trabalho em seu aprendizado, demonstrando que a principal contribuição do projeto foi no entendimento dos conceitos aprendidos nas aulas durante 0 ano de 2020.

Palavras-chave: Ensino de Engenharia, Tecnologia de ensino, Ensino por projetos. 


\section{COMO OS ALUNOS DE ENGENHARIA ELÉTRICA PODEM SE INTERESSAR POR MECÂNICA DAS ESTRUTURAS?}

\section{INTRODUÇÃO}

A aula expositiva não é a única técnica disponível para a transmissão de informações, embora seja a mais utilizada.

Conforme evidenciado por Masetto (2012), há outras técnicas que estimulam a expressão do aluno como sujeito ativo na aquisição do conhecimento e no desenvolvimento de habilidades tão necessárias neste século XXI. Recursos audiovisuais e textos complementares para leitura são técnicas frequentemente disponibilizadas para motivar os alunos, apoiando as aulas expositivas ou outras. Os debates, as dramatizações e as dinâmicas de grupo permitem que o aluno expresse suas ideias e experiências por meio do diálogo. Os estudos de caso colocam o aluno em contato com situações profissionais reais ou possíveis, que incentivam o aprendizado por meio de simulações concretas, auxiliando no desenvolvimento da capacidade de analisar problemas e encontrar soluções, estimulando o trabalho em grupo e o enfrentamento de situações reais.

As estratégias de ensino com pesquisa e por projetos requerem uma dedicação maior fora do horário das aulas. Em ensino com pesquisa, os alunos são apresentados à importância da pesquisa e a sua relação com o aprendizado e, em seguida, recebem a atribuição de produzir um relatório sobre algum tema específico a ser pesquisado. Em ensino por projetos, no entanto, o aluno é estimulado a atribuir metas e objetivos para a realização de um projeto, com atenção ao tempo, às responsabilidades dos participantes, aos recursos e às estratégias. Para finalizar o processo, recomenda-se a realização de uma apresentação final, que será também um momento de aprendizagem e não apenas um encerramento dos trabalhos desenvolvidos (MASETTO, 2012).

$O$ processo de ensino por projetos tem destaque especial no que se refere à capacidade de engajar os alunos ativamente em seu aprendizado e vem sendo altamente recomendada como uma das melhores práticas educacionais neste século (BENDER, 2012), pois relaciona a teoria com a prática. Consequentemente, este método pode ser implementado em disciplinas exclusivamente teóricas, fornecendo um dinamismo e uma aplicação aos conteúdos vistos em aulas.

O presente artigo tem como objetivo descrever os resultados dessa estratégia na disciplina "Fundamentos de Mecânica das Estruturas (PEF 3208)", ministrada na Escola Politécnica da Universidade de São Paulo (Poli USP) no ano de 2020 para alunos do curso de graduação em Engenharia Elétrica. Os temas dos projetos, elaborados em grupos de 2 a 4 alunos, foram propostos livremente e o requisito era de que o cenário fosse a Mecânica das Estruturas.

Ao se avaliar os resultados da pesquisa sobre a percepção destes alunos quanto à contribuição do trabalho no aprendizado da disciplina pode se concluir o acerto da adoção dessa estratégia.

\section{REFERENCIAL TEÓRICO}

O aprendizado de um aluno não se restringe ao momento da aula. Aprende-se a todo momento, desde que a aprendizagem seja "significativa, integradora, diversificada, ativa, socializadora" (PACHECO, 2014, p.11). Em adição, o ato de ensinar, além de segurança 
e competência do professor, também demanda estimular a capacidade crítica do aluno, ensinando o conteúdo e atitudes éticas (FREIRE, 2009).

Assim, a aprendizagem ativa vem se destacando como forma de educação autônoma, na qual o aluno participa ativamente do seu próprio processo de aprendizagem. Dessa forma, o aluno é o principal construtor do seu conhecimento, sendo levado a descobrir um fenômeno e a compreender por si só os conceitos acerca desse fenômeno. Dessa forma, o conhecimento tende a exercer um maior significado para o aluno e, portanto, a informação é mais facilmente retida (VILLAS-BOAS et al., 2012).

$\mathrm{Na}$ Aprendizagem Ativa, através de atividades baseadas em projetos, colaborativas e centradas em soluções de problemas, os estudantes desempenham um papel vital na criação de novos conhecimentos que podem ser aplicados a outras áreas acadêmicas e profissionais (VILLAS-BOAS et al., 2012, p.9).

O Ensino por Projetos, também denominado Aprendizagem Baseada em Projetos (ABP), é uma abordagem teórico-metodológica que estimula o aluno a desenvolver um projeto baseado em questões reais que considerem significativas, sendo o professor um colaborador desse processo (BENDER, 2012). Deve-se traçar os objetivos do projeto, suas expectativas, etapas de realização, a metodologia que será utilizada, o tempo de trabalho e as metas parciais e finais. Em caso de projetos em grupo, também é necessário estabelecer os participantes, suas ações e responsabilidades. Além disso, o ABP também tem como objetivo pôr em prática os conteúdos aprendidos, relacionando diversas disciplinas e, consequentemente, desenvolvendo habilidades interdisciplinares, integrando conhecimentos de diferentes áreas (MASETTO, 2012).

Alguns termos cruciais para o entendimento da técnica foram apresentados por Bender (2012) e estão descritos na Tabela 1.

Tabela 1 - Principais termos da Aprendizagem Baseada em Projetos

\begin{tabular}{|c|c|}
\hline Termo & \multicolumn{1}{|c|}{ Definição } \\
\hline Âncora & $\begin{array}{c}\text { Fundamenta a proposta de ensino em um cenário real. São as } \\
\text { referências e motivações que instituem o tema do projeto, como } \\
\text { notícias de jornal, um vídeo interessante etc. }\end{array}$ \\
\hline Artefatos & $\begin{array}{r}\text { Material criado durante o desenvolvimento do projeto, } \\
\text { representando seu problema ou solução. Os artefatos não } \\
\text { necessitam ser entregues exclusivamente em formato de } \\
\text { relatório escrito ou apresentação. }\end{array}$ \\
\hline Brainstorming & $\begin{array}{c}\text { Técnica de geração de ideias para planejamento do projeto. } \\
\text { Deve-se enumerar o maior número de ideias possível, sem } \\
\text { julgamento prévio. }\end{array}$ \\
\hline Pergunta diretora & $\begin{array}{c}\text { Refere-se ao questionamento que determina o objetivo principal } \\
\text { do projeto. Proposta pelo professor, deve ter caráter motivacional } \\
\text { e incentivador. }\end{array}$ \\
\hline Aprendizado exploratório & $\begin{array}{c}\text { É uma forma de ensino por projetos pouco recorrente que } \\
\text { envolve visitação de locais da comunidade relacionados ao }\end{array}$ \\
\hline
\end{tabular}




\begin{tabular}{|c|c|}
\hline Voz e escolha do aluno & $\begin{array}{c}\text { Os discentes devem ter algum poder de decisão no que se refere } \\
\text { à escolha do projeto e à elaboração da Pergunta Diretora. }\end{array}$ \\
\hline Web 2.0 & $\begin{array}{c}\text { Utilização de ambientes tecnológicos não só para buscas de } \\
\text { conceitos na internet, mas como ferramenta do projeto para } \\
\text { criação de novos conhecimentos. }\end{array}$ \\
\hline
\end{tabular}

Fonte: Bender, 2012

A técnica de Ensino por Projetos, quando aplicada aos cursos de Engenharia, é capaz de desenvolver no aluno diversas competências esperadas para o futuro engenheiro, como interação por meio de trabalho colaborativo, aplicação de conteúdos teóricos, capacidade de resolução de problemas e apresentação de resultados (SILVIA, 2019). Possibilita também o desenvolvimento das competências definidas pelas Diretrizes Curriculares de Engenharia publicadas em abril de 2019.

\section{METODOLOGIA}

\subsection{A Disciplina}

Na estrutura curricular, a disciplina PEF 3208, de dois créditos, está contida no terceiro período ideal (semestre) para os alunos de Engenharia Elétrica e não possui prérequisitos. Há quatro professores que assumem cada uma das quatro turmas em que os 240 alunos são distribuídos.

Os objetivos para os alunos, conforme disposto no Plano de Ensino da disciplina, são: a aquisição de conhecimentos básicos de Mecânica das Estruturas para dialogar com engenheiros de outras habilitações, apresentando-se os conceitos de esforços solicitantes, tensões, deformações e deslocamentos através de exemplos qualitativos; o desenvolvimento das habilidades de identificação de problemas no cotidiano da Engenharia Elétrica, de trabalho em equipe e de comunicação; a valorização da postura ética, das atitudes responsáveis e o reconhecimento da importância da Resistência dos Materiais na formação geral do engenheiro.

Ao final do semestre, espera-se que os alunos tenham adquirido os seguintes conhecimentos:

- Esforços solicitantes: mecânica das estruturas; objetivos da Resistência dos Materiais; classificação das estruturas; classificação das ações: esforços, variações de temperatura e recalques de apoio; estruturas isostáticas; determinação dos esforços reativos e solicitantes; linhas de estado; vigas retas; vigas poligonais; treliças planas isostáticas; cálculo de treliças pelo equilíbrio dos nós.

- Tensões e deformações: resultados experimentais; lei de Hooke; coeficientes de segurança; tensões admissíveis; tração e compressão simples; corte puro; características geométricas das figuras planas; tensões normais e de cisalhamento na flexão simples normal; equação diferencial da linha elástica; flambagem: casos fundamentais de Euler; torção: barras de seção circular e anular. 


\subsection{As Avaliações}

Os alunos foram avaliados por duas provas e um projeto em forma de trabalho obrigatório em equipe com intervalo de notas de 0 a 10. A média final M é a média aritmética simples. Se as notas das provas são P1 e P2 e a nota do projeto é T, então

$$
M=(P 1+P 2+T) / 3
$$

A mesma prova foi aplicada às quatro turmas em um mesmo horário. Essas provas foram realizadas no meio e no fim do período letivo e continham três questões analíticoexpositivas sobre os assuntos abordados na disciplina. Para os alunos que faltaram a uma das duas provas foi oferecida uma prova substitutiva.

Se o projeto, que é o trabalho em equipe, não foi entregue ou se (P1 + P2) foi menor que 8,0, então $T$ é igual a zero. A nota do trabalho foi considerada para casos em que a soma das duas provas fosse maior ou igual a oito. Caso o aluno não atingisse a média final maior ou igual a cinco, era aplicada uma outra prova na última semana de férias, chamada de recuperação. Sendo $R$ a nota nessa recuperação, o aluno foi aprovado se $(0,5 M+0,5$ R) foi maior ou igual a 5,0 .

\subsection{O Projeto}

As orientações para o projeto foram divulgadas acompanhadas de alguns exemplos de trabalhos apresentados por turmas de anos anteriores.

Os objetivos do projeto foram o desenvolvimento das habilidades de trabalho em equipe e de comunicação dos alunos, além do comprometimento com a qualidade de suas atividades, do domínio da língua inglesa e das ferramentas básicas de informática, da capacidade de planejamento, da responsabilidade e da interdisciplinaridade.

Algumas sugestões dadas:

Confecção de um modelo físico para o aprendizado da Resistência dos Materiais, acompanhado do memorial descritivo e do projeto executivo.

- Verificação de uma estrutura como uma ponte adotando os seguintes procedimentos:

1) apresentação de um modelo simplificado traduzindo as principais condições da estrutura construída, definindo as hipóteses simplificadoras assumidas; 2) determinação das características geométricas de uma seção transversal; 3) pesquisa dos pontos de maior momento fletor para o carregamento especificado; 4) cálculo das reações de apoio considerando os materiais utilizados na estrutura.

- Montagem de apresentações de um tópico de Resistência dos Materiais utilizandose recursos de multimídia, pôsteres etc.

- Elaboração de material de consulta para o estudo de Resistência dos Materiais: glossário, formulário, esquemas de seções etc. 
- Elaboração de um programa de computador que auxilie o aprendizado da disciplina ou facilita os cálculos.

Para auxiliar na condução do trabalho, solicitou-se que os alunos entregassem a proposta do trabalho na semana anterior à primeira prova.

As apresentações dos trabalhos foram realizadas de forma remota para toda a turma duas semanas antes da segunda prova, situada no fim do período. A versão em arquivo do trabalho também foi depositada como tarefa nesse dia.

A nota do trabalho $(\mathrm{T})$ foi determinada pelos próprios alunos da turma por meio de votação em uma cédula, na qual atribuíam os conceitos para os projetos de cada equipe com exceção da própria (Figura 1). Foram considerados alguns aspectos importantes, como a qualidade da apresentação, aplicação dos conceitos de Resistência dos Materiais, o potencial desafiador do trabalho, a criatividade do grupo e o tempo de dedicação.

Dos trabalhos apresentados na turma 3, podem ser citados os que tiveram como tema a Barragem de Itaipu no Brasil e a estrutura Maeslantkering na Holanda (Figura 2), o suporte de instrumentos de corda (Figura 3), a escultura Penrose (Figura 4) em que foi construído um modelo físico com Lego, o andaime suspenso (Figura 5) em que se propôs uma solução para evitar acidentes, o controle da guitarra (Figura 6), a cadeira de escritório e um homem levantando peso (Figura 7) e, por fim, o robô da NASA Rocker-Bogie (Figura 8).

Figura 1 - Notas atribuídas por um aluno aos trabalhos dos demais grupos.

\section{PEF 3208 Fundamentos de Mecânica das Estruturas}

Solicito a participação de todos na atribuição de notas aos trabalhos dos outros grupos.

Utilizem a cédula em anexo e depositem no site.

\begin{tabular}{|l|l|c|c|}
\hline Grupo & Tema abreviado & $\begin{array}{l}\text { Apresentação, Conceitos de } \\
\text { Resmat, Desafio, } \\
\text { Criatividade, Tempo de } \\
\text { dedicação }\end{array}$ & $\begin{array}{l}\text { NOTA } \\
\text { De } 5 \text { a 10 }\end{array}$ \\
\hline $\begin{array}{l}\text { G1-Gabriel Nunes, Silas Lima e Silva, } \\
\text { Victor Queiroz }\end{array}$ & Torre de Pisa & $10 / 10 / 8 / 10$ & 9,5 \\
\hline $\begin{array}{l}\text { G2-Gabriel Bonassi, Henrique de Melo, } \\
\text { Victor Silva }\end{array}$ & Contrabaixo & $10 / 10 / 8 / 10$ & 9,5 \\
\hline $\begin{array}{l}\text { G3-Matheus Casagrandi, Julio de Oliveira, } \\
\text { Georgia Saddi }\end{array}$ & Cama & $10 / 10 / 10 / 10$ & 10,0 \\
\hline $\begin{array}{l}\text { G4-Bruno Camara, Isabela de Sordi, Luis, } \\
\text { Carlos Pires }\end{array}$ & Calistenia ou suporte & $10 / 10 / 8 / 10$ & 9,5 \\
\hline $\begin{array}{l}\text { G5-Murilo Alvares, Ivan Dias, Paulo } \\
\text { Parenti Filho, Marcio de Moraes }\end{array}$ & Cadeira & $10 / 10 / 10 / 10$ & 10,0 \\
\hline $\begin{array}{l}\text { G6-Bruna Silva, Carolina Rego, Marco } \\
\text { Santos, Rafael Martins }\end{array}$ & Penrose & $10 / 10 / 10 / 10$ & 10,0 \\
\hline $\begin{array}{l}\text { G7-Bruno de Freitas, Lucca Gamballi, } \\
\text { Pedro Lima }\end{array}$ & Andaime & $10 / 10 / 10 / 10$ & 10,0 \\
\hline G8-Matheus da Silva, Matheus de Oliveira & Torre de Pisa & $10 / 10 / 8 / 10$ & 9,5 \\
\hline G9-Vitor Komar, Hugo Albuquerque & Aqueduto & $10 / 10 / 10 / 10$ & 10 \\
\hline $\begin{array}{l}\text { G10-Enzo Tonelli, Gustavo Oliveira, } \\
\text { Matheus Nunes }\end{array}$ & Torre de Pisa & $10 / 10 / 8 / 10$ & 9,5 \\
\hline $\begin{array}{l}\text { G11-Matheus de Barros, Letícia Kamiha, } \\
\text { Vinicius dos Reis, Giovanni Morales }\end{array}$ & Itaipu & $10 / 10 / 10 / 10$ & 10,0 \\
\hline G12-Vitor Santos & Fórmula 1 & $10 / 10 / 10 / 10$ & 10,0 \\
\hline $\begin{array}{l}\text { G13-Thomás Azevedo e Sá, Guilherme da } \\
\text { Silva }\end{array}$ & Guindaste & $8 / 10 / 10 / 10$ & 9,5 \\
\hline $\begin{array}{l}\text { G14-Caio Gossi, Vinicius Souza, Klisman } \\
\text { Belchior }\end{array}$ & Halterofilismo & $10 / 10 / 10 / 10$ & 10,0 \\
\hline $\begin{array}{l}\text { G15-Fabiano Shimura } \\
\text { Guitarra }\end{array}$ & $10 / 10 / 8 / 10$ & 9 \\
\hline
\end{tabular}


Figura 2 - Estruturas de contenção de águas: Itaipu e Maeslantkering.
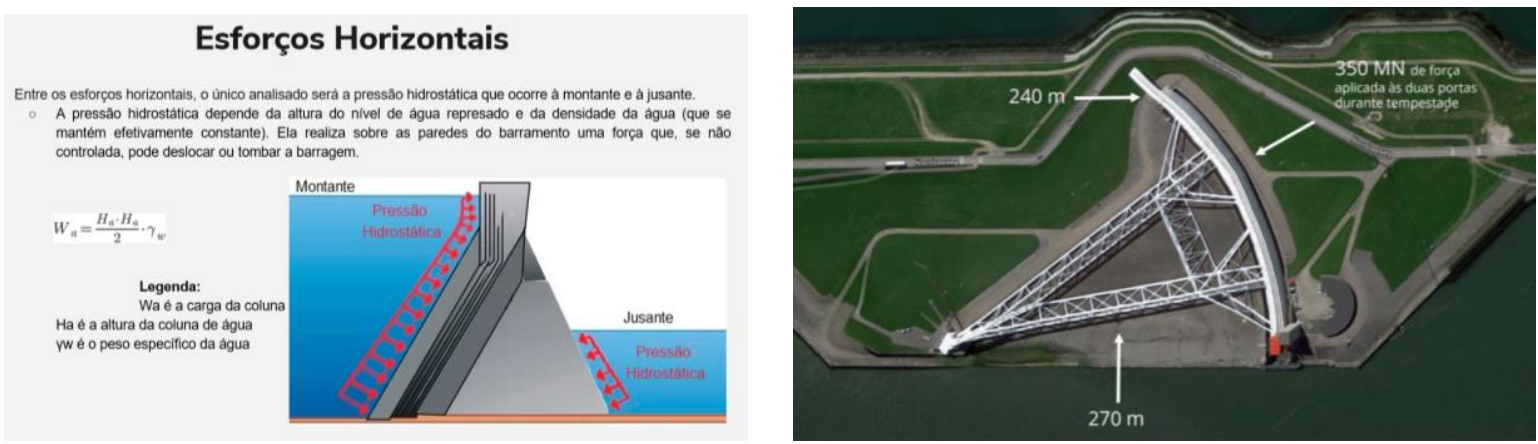

Figura 3 - Suporte de instrumento de corda e esboço dos diagramas.
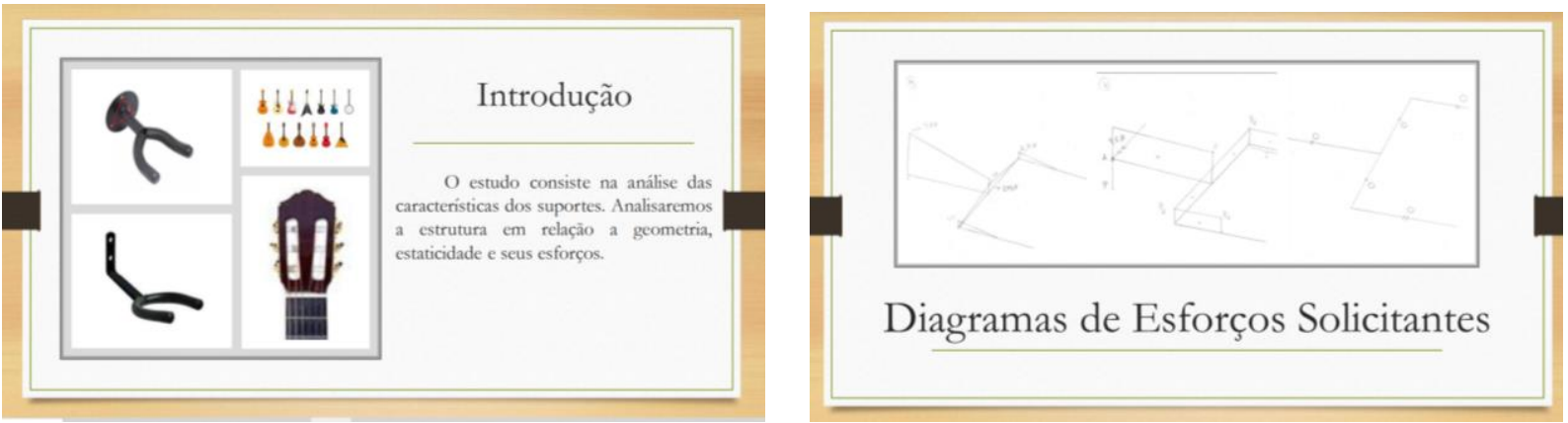

Figura 4 - Penrose e modelo físico com LEGO.

Model0 30

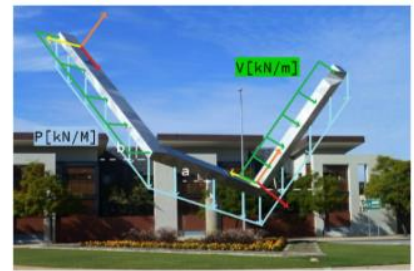

Barra Poligonal
um único ponto

3 Barras de comprimento 5d,

$3 d, 4 d$

- Ángulos b,a

- Cargas Distribuidas P e
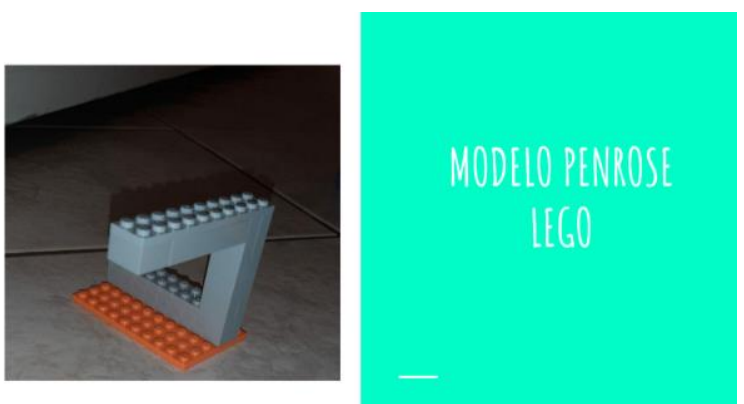
Figura 5 - Andaime suspenso submetido a fortes ventos.
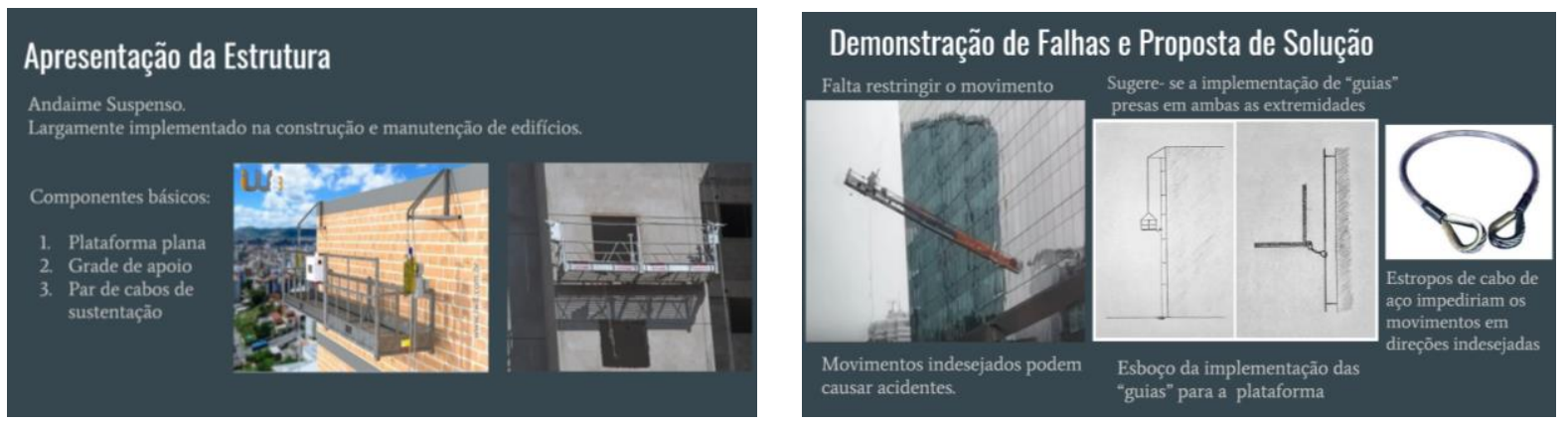

Figura 6 - Controle da guitarra.

2.1 Visão Geral

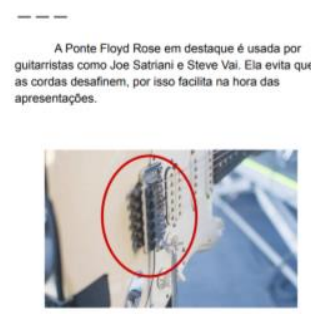

$$
\begin{aligned}
& \text { A figura aba } \\
& \text { (cor roatead } \\
& \text { equilibrio. } \\
& \text { Uma força } F
\end{aligned}
$$

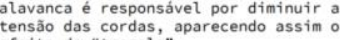
to "tremolo".

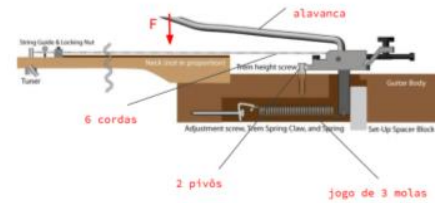

\section{Medidas e valores}

$---$

3.1 Pesquisa bibliográfica

Visão Frontal: Forças

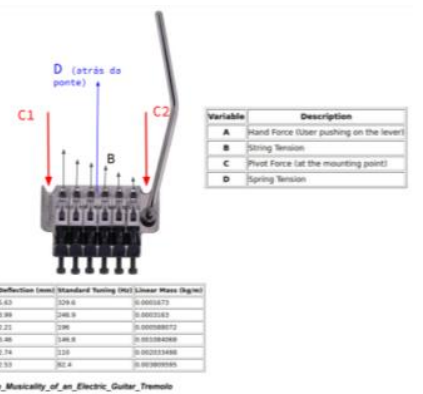

Figura 7 - Cadeira de escritório e levantamento de peso, modelo matemático e aplicação do Ftool para obtenção dos diagramas dos esforços solicitantes.

Planejamento

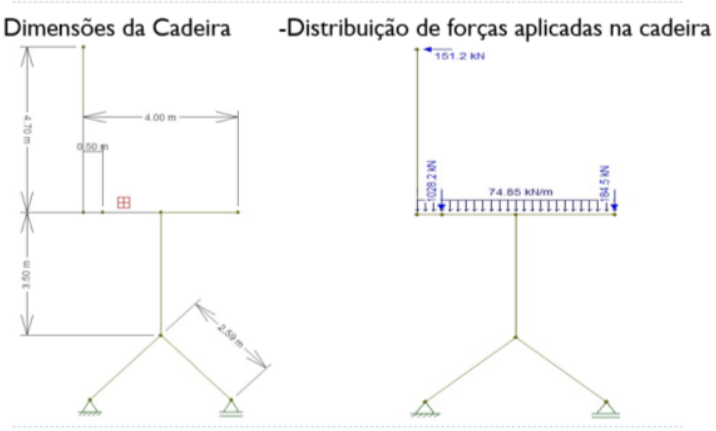

Modelagem da estrutura

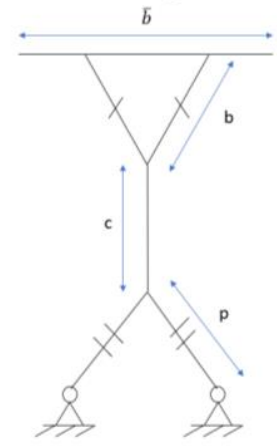

- Dados iniciais:

$$
\begin{aligned}
& \bar{b} \text {-tamanho da barra; } \\
& \mathrm{b} \text { - tamanho dos braços; } \\
& \mathrm{c} \text { - tamanho da coluna; } \\
& \mathrm{p} \text { - tamanho das pernas. }
\end{aligned}
$$


Figura 8 - Rocker-Bogie e o diagrama do momento fletor correspondente.

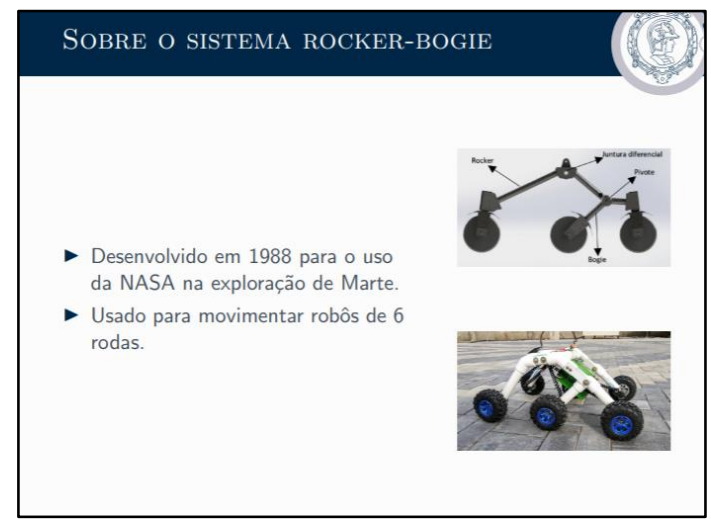

Diagrama DO MOMEnTo Fletor

No fim do semestre, os alunos foram questionados sobre a contribuição do trabalho no aprendizado da disciplina por meio de uma enquete. A pesquisa era avaliada em notas de 1 (muito ruim) a 5 (muito bom). As perguntas realizadas na enquete estão dispostas na tabela 2.

Tabela 2 - O trabalho contribuiu...

\begin{tabular}{|l|l|}
\hline Pergunta 1 & na fixação do vocabulário? \\
\hline Pergunta 2 & no entendimento dos conceitos? \\
\hline Pergunta 3 & na motivação para o aprendizado? \\
\hline
\end{tabular}

\section{RESULTADOS}

O projeto proposto e executado na disciplina em questão evidencia alguns dos princípios cruciais dispostos por Bender (2012). No arquivo de orientação enviado aos alunos, o professor estipula como âncora a realização de um projeto relevante aos temas já apresentados durante as aulas da disciplina. Este é um exemplo claro de união do teórico e do prático, no qual a fundamentação da atividade prática tem sua origem nos ensinamentos teóricos.

A orientação do projeto não apresentou uma pergunta diretora no sentido único, mas exemplos de possibilidades de projetos e possíveis referências, permitindo ao aluno a escolha do tema, dos conteúdos abordados e ainda dos artefatos a serem utilizados para a transmissão do conhecimento. Há também o estímulo à utilização de ferramentas de tecnologia para composição do trabalho, como recursos de multimídia, simuladores ou programas de computador que auxiliem no aprendizado da disciplina ou facilitem os cálculos.

Nessa dinâmica, o professor apresentou papel de observador e orientador, no sentido de um sujeito que indica ou ajusta com referência a um ponto, a um objetivo. Percebe-se, inclusive, que não coube ao professor a atribuição das notas, mas sim à turma, retirando do mesmo o caráter autoritário que lhe é normalmente dado.

Não houve participação do professor com relação à elaboração do trabalho por parte dos grupos, exceto quando solicitado. Assim, não foram abordadas técnicas como 
brainstorming ou aprendizado exploratório, inibido pela pandemia do coronavírus e o caráter remoto da disciplina no ano de 2020.

A avaliação realizada após o final do período, revelou a percepção de 51 (cinquenta e um) estudantes com relação à metodologia de Ensino por Projeto. Vale ressaltar que a participação dos alunos na avaliação foi opcional. Conforme evidenciado na Tabela 3, a principal contribuição atribuída ao trabalho foi a de auxílio no entendimento dos conceitos, para o qual mais da metade dos participantes conferiu nota máxima, atingindo média 4.3 de um máximo igual a 5.0.

Em segundo lugar, os alunos consideraram que a realização do trabalho ajudou na motivação para o aprendizado, apresentando uma média de 4.1 na escala de concordância. Por fim, a fixação do vocabulário (média $=4.0$ ) obteve moda nota 4 .

Tabela 3 - O trabalho contribuiu... (Respostas por quantidade de alunos).

\begin{tabular}{|c|c|c|c|c|c|c|c|}
\hline & $\mathbf{1}$ & $\mathbf{2}$ & $\mathbf{3}$ & $\mathbf{4}$ & $\mathbf{5}$ & total & média \\
\hline na fixação do vocabulário? & 0 & 4 & 9 & $\mathbf{2 1}$ & $\mathbf{1 7}$ & 51 & 4.0 \\
\hline no entendimento dos conceitos? & 1 & 0 & 8 & 16 & $\mathbf{2 6}$ & 51 & 4.3 \\
\hline na motivação para o aprendizado? & 1 & 2 & 11 & 12 & $\mathbf{2 5}$ & 51 & 4.1 \\
\hline
\end{tabular}

\section{$5 \quad$ CONCLUSÕES}

A adoção da técnica de Aprendizagem por Projetos na disciplina de Fundamentos de Mecânica das Estruturas apresentou resultados positivos com relação à absorção dos conteúdos teóricos fornecidos em sala de aula. Os alunos expressaram os conhecimentos aplicando em casos reais, de objetos/estruturas/situações cotidianas.

Todos os trabalhos abordaram os temas de esforços reativos e solicitantes nem sempre de forma correta. Algumas variações foram notadas na escolha das cargas e na abordagem adotada.

A interdisciplinaridade esteve presente nos trabalhos, tanto nos temas adotados, quanto nos artifícios utilizados, que variaram de vídeos com imagens aéreas a animações 2D.

Segundo Ji e Bell (2014), motivar e envolver os alunos é mais do que melhorar as aulas e a avaliação final da disciplina e alguns dos trabalhos que têm a essência da aprendizagem defendida por Holzer et Andruet (2000) demonstram o acerto da estratégia adotada na disciplina.

Por fim, a avaliação realizada com os alunos revelou que a principal contribuição do trabalho foi o entendimento mais aprofundado dos conceitos aprendidos em sala, o que traz a técnica $\mathrm{ABP}$ como um complemento prático para o entendimento da física envolvida.

\section{REFERÊNCIAS}

BENDER, W. N. Project-Based Learning: Differentiating Instruction for the 21st Century. 1. ed, California: Corwin, 2012. 
FREIRE, P. Pedagogia da Autonomia. 25. ed, São Paulo: Paz e Terra, 2002.

HOLZER, S. M.; ANDRUET, R. H. Experiential Learning in Mechanics with Multimedia, The International Journal of Engineering Education, v. 16, n. 5, 2000, ISSN 0949-149X.

JI, T.; BELL, A. J. Innovative teaching and learning of structural concepts. The Institution of Structural Engineer, London, v. 92, n. 9, p. 10-14, 2014.

MASETTO, M. T. Competência Pedagógica do Professor Universitário. 2. ed, São Paulo: Summus, 2012.

PACHECO, J. Aprender em Comunidade. 1. ed, São Paulo: Edições SM, 2014.

SILVA, R. M. R. Aprendizagem Baseada em Projetos: Um Olhar sobre a Experiência da Implementação da ABP em um Curso de Engenharia. Dissertação (Mestrado em Educação em Ciências) - Instituto de Ciências Básicas da Saúde, Universidade Federal do Rio Grande do Sul. Porto Alegre, 2019.

UNIVERSIDADE DE SÃO PAULO. Disciplina: PEF3208 - Fundamentos de Mecânica das Estruturas. Informações da Disciplina. Júpiter - Sistema de Gestão Acadêmica da PróReitoria de Graduação. Disponível em: <https://uspdigital.usp.br/jupiterweb/obterDisciplina?nomdis=\&sgldis=PEF3208>. Último acesso: $7 / 6 / 2021$.

Sistemas Computacionais. Disponível em:
$<$ https://uspdigital.usp.br/jupiterweb/listarGradeCurricular?codcg=3\&codcur=3032\&codhab $=3180 \&$ tipo=N $>$. Último acesso: 6/5/2021.

. Grade Curricular. Habilitação: Engenharia Elétrica - Ênfase em Energia e Automação Elétricas. Disponível em: $<$ https://uspdigital.usp.br/jupiterweb/listarGradeCurricular?codcg=3\&codcur=3032\&codhab $=3190 \&$ tipo=N $>$. Último acesso: 6/5/2021.

Grade Curricular. Habilitação: Engenharia Elétrica - Ênfase em Telecomunicações. =3160\&tipo=N>. Último acesso: 6/5/2021.

Projeto (Trabalho em Equipe) - Orientações. Disponível em: <https://edisciplinas.usp.br/pluginfile.php/6114410/mod_resource/content/1/2021Texto\%2 Otrabalho\%20grupo.pdf>. Último acesso: 7/6/2021.

VILLAS-BOAS, V. et al. Desafios da educação em engenharia: vocação, formação, exercício profissional, experiências metodológicas e proposições. p. 59-112, 1. ed, Brasília/Blumenau: ABENGE/EdiFURB, 2012.

\section{HOW CAN ELECTRICAL ENGINEERING STUDENTS GET INTERESTED IN} STRUCTURAL MECHANICS? 
Abstract: Project-Based Learning (PBL) stands out in terms of the ability to actively engage students in their learning and has been highly recommended as one of the best educational practices of the 21st century. This article aims to analyze PBL methodology in the "Fundamentals of Structural Mechanics course (PEF 3208)", taught at Escola Politécnica in Universidade de São Paulo (Poli USP) and mandatory for students in the third semester of Electrical Engineering's undergraduate degree. Final projects were analyzed in terms of contemplation of the topics expected in the program of studies. Also, the students were surveyed on their perception of the project's contribution to their learning experience. Results agree that students believe that the project's main contribution was to understand the concepts learned in the classroom during 2020.

Keywords: Teaching of Engineering, Teaching techniques, Project-Based Learning. 